\author{
コンパクトピコ秒パルスラジオリシスシステムを用いた \\ 紫外固体レーザー結晶 $\mathrm{Ce}^{3+}: \mathrm{LiCaAlF}_{6}$ の \\ 電子線パルス励起による特性評価
}
鈴木 祐仁*,**，小関 俊政 $*$,**, 大竹秀幸 $*$,**, 猿倉 信彦 $*$,**
中條晃伸 $* * *$, 酒井 文雄 $* * *$, 青木 康 $* * *$
*分子科学研究所 ( $7444-8585$ 愛知県岡崎市明大寺町西郷中 38 )
**総合研究大学院大学 (下 240-0193 神奈川県三浦郡葉山町 \{湘南国際村\})
****住友重機械工業(株) 技術開発センター（１１88-8585 東京都西東京市谷戸町2-1-1）

\title{
Evaluation of $\mathrm{Ce}^{3+}$ :LiCaAlF 6 Using a Table-Top-Sized, 3-MeV, Picosecond Electron-Beam Source with a Photocathode
}

\author{
Yuji SUZUKI*,**, Toshimasa KOZEKI*,**, Hideyuki OHTAKE*,** \\ Nobuhiko SARUKURA****, Terunobu NAKAJYO***, Fumio SAKAI***, and Yasushi AOKI*** \\ * Institute for Molecular Science (IMS), Myodaiji, Okazaki 444-8585 \\ ** The Graduate University for Advanced Studies, ShonanVillege, Hayama, Kanagawa 240-0193 \\ *** Sumitomo Heavy Industries, Ltd. R\&D Center, 2-1-1 Yato-Cho, Nishitokyo-City, Tokyo 188-8585
}

(Received June 3, 2002)

\begin{abstract}
A table-top sized hybrid fluorescence spectroscopy system with picosecond, 3-MeV electron-beam from a photocathode and picosecond optical pulses was successfully demonstrated. This system has shown that the properties of an electron-beam pumped Ce:LiCAF: ultraviolet laser medium significantly differ from those of an optically pumped medium. The case of electron-beam pumped, the longer wavelength side of the spectrum is significantly enhanced and the fluorescence lifetime of this medium became slightly longer compared to the optically pumped case. This experimental results suggest that additional potential advantages of electronbeam pumping of Ce:LiCAF for an ultrashort pulse amplifier can be derived from its modified fluorescence spectral shape and longer lifetime.
\end{abstract}

Key Words: $\mathrm{Ce}^{3+}: \mathrm{LiCaAlF}_{6}$, Ultraviolet, Electron-beam, Pulseradiolysis, Spectroscopy

\section{1.はじめに}

電子線パルスを用いた時間分解分光(パルスラジオリシ ス)は，新しい時間分解分光法として有用であり，今後大 きく発展していく研究分野であると考えられる．時間分 解能について他の光源を用いた時間分解分光法と比較す ると，レーザーパルスを用いた場合の時間分解能は，東 京大学小林孝嘉教授らによって5フェムト秒以下のレベル にまで到達しているが1), 電子線パルスの時間分解能は, 東京大学上坂充教授らによってようやくサブピコ秒レベ ルに達したのが現状である2).しかしながら，レーザーパ ルスの時間分解能は既に限界に近い領域にまで達してい るのに対して, 電子線パルスに関してはまだ十分に短パ ルス化する余地が残されており, また新たな時間分解分 光法としての可能性も秘めている.

過去のパルスラジオリシスシステムに関する研究につ いては, 線形加速器を用いた研究の報告がなされてい
る3-5)。しかし過去に報告されたパルスラジオリシスシス テムは, 熱電子銃から発生する電子ビームをピコ秒の短 パルス電子ビームに圧縮するために，プリバンチャー， バンチャー及び加速用のリニアックを設ける必要がある ため, システムが複雑となるばかりでなく, 加速器全体 が大型となる。これらの問題が電子線パルスによる時間 分解分光の汎用性を低くし, この分野の発展を妨げる要 因となっていた。

今回共同研究先である住友重機械工業株式会社は, フォトカソードRF電子銃を利用したピコ秒電子線パルス 発生装置を開発した。この装置は, 他のシステムと比較 して, 電子ビーム圧縮システムが不要であるため, 小型 となる6,7)。このシステムにより, 実験室レベルでの電子 線パルスによる時間分解分光が可能となった。 今回の報 告ではこのパルスラジオリシスシステムを用いて, 我々 が研究を進めている紫外固体レーザー結晶 $\mathrm{Ce}^{3+}: \mathrm{LiCaAlF}_{6}$ (Ce:LiCAF)に電子線パルスを照射して励起した場合の発 
光特性を評価し, 電子線パルス励起による大出力紫外固 体レーザー実現の可能性を調べた.

本解説では, はじめに試料であるCe:LiCAFについて記 し, 過去に行ったCe:LiCAFの励起チャンネルの発見, パ ルスラジオリシスシステム, 実験結果, まとめの順に解 説する。

\section{2. $\mathrm{Ce}^{3+}: \mathrm{LiCaAlF}_{6}(\mathrm{Ce}: \mathrm{LiCAF})$}

$\mathrm{Ce}^{3+}: \mathrm{LiCaAlF}_{6}(\mathrm{Ce}: \mathrm{LiCAF})$ は，1993年に共同研究者であ るロシアのM. A. Dubinskii教授によって発見された紫外 レーザー結晶であり, 中心波長 $290 \mathrm{~nm}$ で発振し, $280 \mathrm{~nm}$ 〜320 nmまでの波長可変性を有する。またこれまでに潮 解性やへき開性などの劣化に関する報告例がない非常に 優れた結晶である ${ }^{8)}$. Ce:LiCAFは, 広いバンド幅を持つこ とから超短パルス化が可能であり，また励起光に対する ダメージしきい值が高く, 強励起可能であることから, 超短パルス高出力紫外レーザー結晶として有用であるこ とが分かっている. 報告例として, 出力に関しては直径 $1.5 \mathrm{~cm}$ のCe:LiCAFを用いることにより, 波長 $290 \mathrm{~nm}$, 繰 り返し周波数 $10 \mathrm{~Hz}$ で最大出力 $60 \mathrm{~mJ}$ 実現している9)。ま た, 最近の研究では同軸励起の増幅器の開発に成功して いる. Ce:LiCAFは左右から4本の波長 $266 \mathrm{~nm}$ のビームに よって合計0.38 JのエネルギーでCe:LiCAFを励起し, $13 \mathrm{~mJ}$ の入力パルスに対して, 最大で $25 \%$ の取り出し効率で 98 $\mathrm{mJ}$ の出力エネルギーを得ることに成功した. 現在, 東北 大学福田 承生教授との共同研究により, 直径 $7 \mathrm{~cm}$ 程度の 非常に大きなCe:LiCAFを育成することが可能となってお り ${ }^{10)}$, 巨大なCe:LiCAFを用いることによって更なる高出 力化への可能性が開かれた. また超短パルス化において は, 我々は紫外領域において世界初のChirped-pulse amplification (CPA) システムを構築し, 波長 $290 \mathrm{~nm}$ で100フェム ト秒レベルの超短パルス化に成功している11)。この報告 をした時点では，120フェムト秒までパルス幅を狭めてい るが, 更なる最適化を行うことによって数十フェムト秒 レベルまでパルス幅を狭くすることが可能になるのと同 時に, 世界初のテラワットレベルの超短パルス紫外固体 レーザーが実現する．現在テラワットレベルの固体紫外 レーザーは実現可能な段階に達しており, 工業応用可能 な光源として新たな段階に入ったと言える。

\section{3. 新しい励起チャンネルの発見と 電子線パルス励起への経緯}

Ce:LiCAFの発振中心波長である $290 \mathrm{~nm}$ における励起 チャンネルを調べるために, 分子科学研究所のUVSORの 放射光をCe:LiCAFに照射して, Photo-luminescence excitation (PLE) 測定を行った結果をFig. 1に示す。この結果か ら, Ce:LiCAFの発振中心波長である $290 \mathrm{~nm}$ に対する励起 チャンネルは, 現在励起光として用いている波長 $266 \mathrm{~nm}$ 付近である $269 \mathrm{~nm}$ の他にも $171 \mathrm{~nm}$ と $112 \mathrm{~nm}$ に励起チャン ネルが存在することを確認した ${ }^{12)}$. ここで励起チャンネ ル $269 \mathrm{~nm}$ と $171 \mathrm{~nm}$ はCe $\mathrm{e}^{3+}$ イオンの吸収に一致している。こ

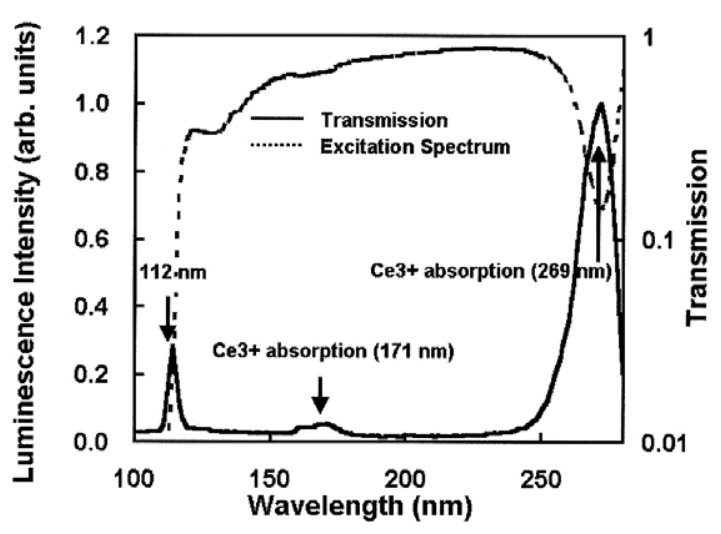

Fig. 1 The excitation spectrum and transmission curve for the Ce:LiCAF crystal. The transmission edge 112 $\mathrm{nm}$ corresponded to the peak of excitation spectrum.

の他に発見された波長 $112 \mathrm{~nm}$ の励起チャンネルは母結晶 であるLiCAFの透過端波長と一致することから，これは母 結晶LiCAFで吸収された電子励起エネルギーのCe ${ }^{3+}$ イオン への移動が行われていると考えられる。このエネルギー 準位に関するダイアグラムをFig. 2に示す。このダイアグ ラムは，母結晶LiCAFを励起することにより $\mathrm{Ce}^{3+}$ イオンを 励起することが可能であることを示唆している．以上の 結果から，現在励起波長として用いている $266 \mathrm{~nm}$ 以外に も励起チャンネルが短波長側に2つあることを発見した。

しかしながらこれらの励起チャンネルを効率よく励起 することのできる実用的なレーザーは現時点で存在しな い.そこで我々は電子線パルスで励起することを考案し た. 電子線パルスはレーザーパルスで励起不可能な励起 チャンネル $112 \mathrm{~nm}$ なら゙に母結晶LiCAFの透過端波長以下 を励起できる可能性を有し, またCe:LiCAFが放射光を照 射することによって劣化が起こらなかったことから, 電 子線パルス励起によるCe:LiCAFレーザーの可能性を見出 すことができた。

ここで電子線パルス装置の問題が出てくるが，これは 先に述べたように，住友重機械工業(株)が非常に優れたパ ルスラジオリシスシステムの開発に成功している。この システムは大きさ $2 \mathrm{~m} \times 3 \mathrm{~m} \times 1.5 \mathrm{~m}$ 程度の, 従来のパルス ラジオリシスシステムに比べて非常にコンパクトなサイ ズであり，かつピコ秒レベルの時間制御性を持つ, レー ザー励起フォトカソード電子線パルス放射装置である。

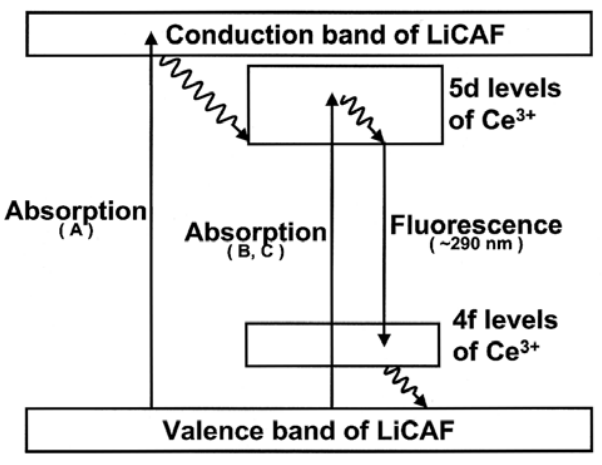

Fig. 2 Schematic of energy levels and possible decay channel in Cerium ion doped crystal. 
このシステムを使用することにより，今まで不可能で あった実験室レベルでのパルスラジオリシスが可能にな り, また実験室レベルでの電子線パルス励起による大出 カレーザーが実現する.

我々はCe:LiCAFの電子線パルス励起による光学特性を 評価することにより, 電子線パルス励起による大出力Ce: LiCAFレーザー実現の可能性を調べた。

\section{4. パルスラジオリシスシステム}

パルスラジオリシスシステムをFig. 3に示す. 電子線パ ルスを放射するフォトカソードRFガンのカソード部に, 低ジッターに改良した79.33 MHzのモードロック Nd:YLF レーザーを励起発振器に用いた再生増幅器により, 波長

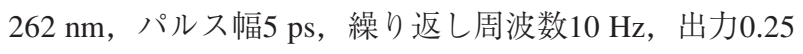
$\mathrm{mJ}$ のレーザーパルスを照射している．また，Nd:YLFレー ザー発振器は, 電子線パルスを加速するために用いられ ている繰り返し周波数 $2.856 \mathrm{GHz}, 6 \mathrm{MW}$ (ピーク電力)の特 性を持つクライストロンと極めて正確に同期させてい る.フォトカソードRFガンは, 銅フォトカソードと1.6セ ルの加速空洞から構成されている. カソード面より放射 された電子線パルスは, カソード直後に設置されている 加速空洞でエネルギー $3.0 \mathrm{MeV}$ まで加速され, ソレノイド マグネットを通過する。このソレノイドマグネットは, 空間電荷によるビームエミッタンスの増大を抑える役割 を果たしている。ソレノイドマグネットによってエミッ タンス補正された電子線パルスは, 後段の収束コイルに よって, 出射口直前に設置されているチタニウム膜の付 近で1 mm径程度まで絞られ, 試料のCe:LiCAFに照射され るように設計されている. 出射口から出てくる電子線パ

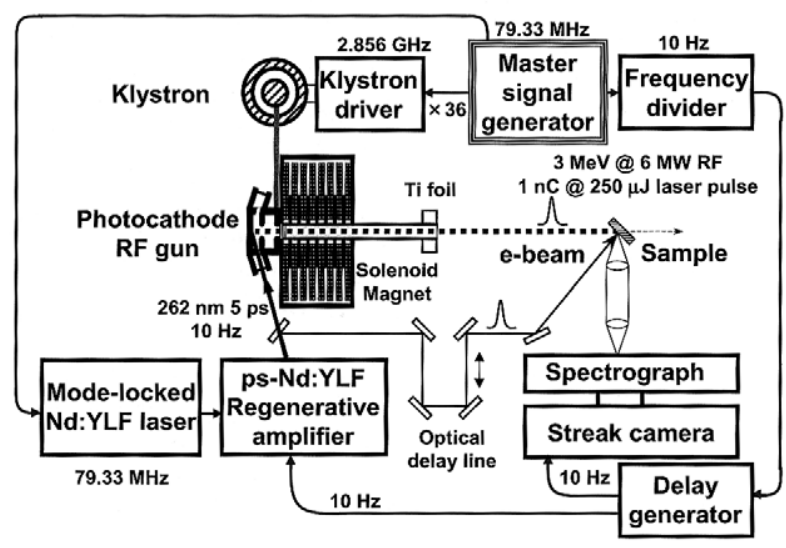

Fig. 3 Experimental setup. The photocathode RF gun was irradiated with 262-nm optical pulses from a Nd:YLF regenerative system synchronously operated with a 2.856-GHz, 6-MW klystron to accelerate the extracted 1-nC photo-electron beam. The e-beam was irradiated onto the sample after being passed through titanium foil. A portion of the pumping optical pulse irradiated the same sample to compare the excitation scheme. A streak camera was equipped with a 30 $\mathrm{cm}$ spectrograph to measure the fluorescence spectrum and fluorescence lifetime.
ルスは, エネルギー $3 \mathrm{MeV}$, 電荷 $1 \mathrm{nC}$, パルス幅 $3 \mathrm{ps}$ の特 性を持っている. 電子線パルス励起によるCe:LiCAFの特 性は, 分光器を通したストリークカメラ (時間分解能 $2 \mathrm{ps}$ ) のストリークカメラ像を用いて, 蛍光スペクトルと蛍光 寿命を測定することにより評価した。また，比較対照と して，フォトカソード照射に用いている $262 \mathrm{~nm}$ 光パルス を同結晶に照射したときに観測される蛍光についても全 く同じ測定系により特性評価を行った.

\section{5. 実験結果}

電子線パルス, ならびにレーザーパルスで励起した場 合のそれぞれの蛍光スペクトルについてのストリークカ メラ像をFig. 4に示す。これより, Ce:LiCAFの蛍光の初期 緩和過程において, 非常に幅広いスペクトルを持つチェ レンコフ放射光も同時に観測できることを確認した。こ こで, チェレンコフ放射光だけを取り出して, そのパル ス幅をストリークカメラの単一パルス計測モードで計測 したところ 15 psであった。 その結果をFig. 5に示す。スト リークカメラの積算計測モードで計測した場合のパルス 幅は30 psであったことから，このシステムの積算計測 モードの持つジッターは2 $2 \mathrm{ps}(\mathrm{FWHM})$ 程度であることが 分かった。これは, レーザーのジッター $0.5 \mathrm{ps}(\mathrm{RMS}), \mathrm{RF}$ のジッター $1.7 \mathrm{ps}(\mathrm{RMS})$ から，ストリークカメラのトリ ガージッターが主因となる $(21.28 \mathrm{ps}(\mathrm{FWHM})$ : ストリーク カメラカタログ值)。このジッターが無視できない場合に は，電子ビーム発生に使用するレーザーをレファレンス 光として発光の光と一緒にストリークカメラに入れ, 解 析的にストリークカメラのトリガージッターを補正させ ることで, 高速現象が解析可能なシステムとなる。

また電子線パルス励起による蛍光スペクトルは, レー ザー励起の場合よりも長波長側のスペクトルが大きく増 幅していることを確認した，更にレーザー励起の場合の

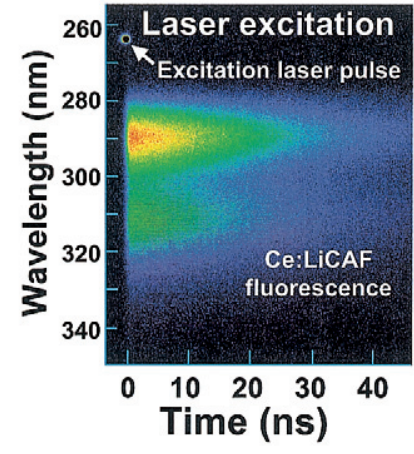

(a)

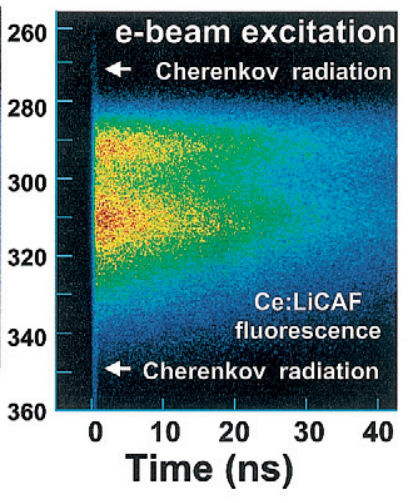

(b)
Fig. 4 The streak camera images of the fluorescence from Ce:LiCAF excited (a) by $262 \mathrm{~nm}$ pulse and (b) by electron pulse. In the case of electron pulse excitation, a broad-band, short-duration Cherenkov radiation is clearly seen. Compared with the optically pumped case in the same setup with a 262-nm optical pulse split from the photo cathode excitation laser, the longer wavelength side of the spectrum is significantly enhanced. 


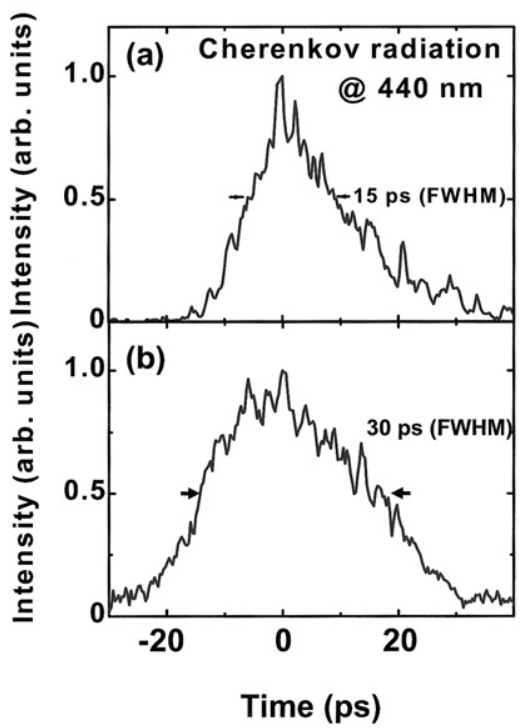

Fig. 5 The time profiles of Cherenkov radiation induced by the electron pulsed beam (a) single shot mode and (b) integration mode, measured by a spectrograph and a streak camera.

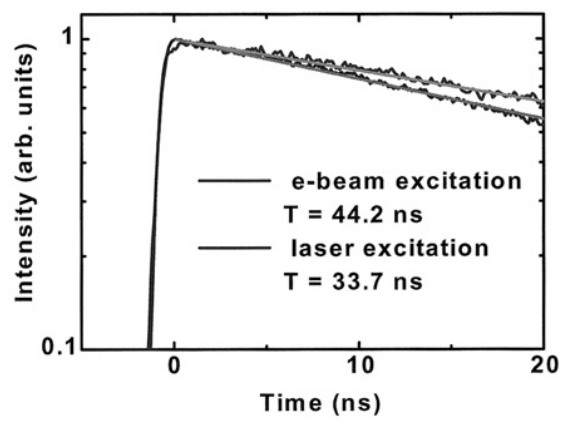

Fig. 6 The fluorescence decay curves of Ce:LiCAF excited by e-beam and by $262 \mathrm{~nm}$ pulse measured around $290 \mathrm{~nm}$. The solid lines indicate the convolution curves with fixed lifetimes, $44.2 \mathrm{~ns}$ for e-beam and $33.7 \mathrm{~ns}$ for $262 \mathrm{~nm}$. The lifetime from e-beam excitation was slightly longer than that from laser excitation.

中心波長は290 nmであったが，電子線パルス励起の場合 の中心波長は，長波長側の増幅により $315 \mathrm{~nm}$ にシフトし ていることも確認した。この結果は電子線パルスとレー ザーパルスそれぞれの励起メカニズムの違いにより, 緩 和過程がそれぞれ異なっていることを示唆していると考 えられる. 次に電子線パルス励起とレーザー励起の各場 合における蛍光寿命についての減衰曲線をFig. 6に示す. この解析は波長 $290 \mathrm{~nm}$ 中心波長とした波長幅 $1 \mathrm{~nm}$ の範 囲をストリークカメラ像より取り出して, その減衰曲線 をプロットし最小二乗法により fittingを行った。 その結 果, 電子線パルス励起の蛍光寿命はfitting結果より 44.2 $\mathrm{ns}$, レーザー励起の場合は $33.7 \mathrm{~ns}$ となり, 電子線パルス励 起のほうがやや蛍光寿命が長くなっていることが分かっ た。この蛍光寿命の違いも先ほど述べた緩和過程の違い により現れていると考えられるが，これらを解明するに は更に研究を進める必要がある。
6. まとめ

住友重機械工業(株)が開発したコンパクトなパルスラ ジオリシスシステムを用いてCe:LiCAFの電子線パルス励 起光学特性を調査した。 その結果よりCe:LiCAFを電子線 パルスで励起した場合の蛍光スペクトルは, レーザー励 起の場合より長波長側が増幅され, 蛍光寿命は電子線パ ルス励起の場合のほうが長くなることが分かった。また Ce:LiCAFの蛍光寿命と同時にチェレンコフ放射光も観測 することができ，チェレンコフ放射光のパルス幅計測か らシステムの持つジッターを評価することができた。更 にCe:LiCAFは電子線パルスで励起可能であることが分か り, 電子線パルス励起による高出力Ce:LiCAFレーザー実 現の可能性を見出すことができた。また，このパルスラ ジオリシスシステムは様々な時間分解分光に用いること ができることが証明され，電子線パルスを用いた時間分 解分光の新たなる可能性を示唆し, 更なる発展が期待さ れる13).

\section{謝 辞}

本研究は, 新エネルギー・産業技術総合開発機構 (NEDO) から研究を委託された技術研究組合・フェムト秒 テクノロジー研究機構 (FESTA) の研究の一環として行わ れたものである. 特に住友重機械工業 (株)の遠藤彰氏に は有益な助言を賜った。 ならびに分子科学研究所の見附 孝一郎先生にも有益な助言を賜った。

\section{参考文献}

1) A. Baltuska, T. Fuji and T. Kobayashi: Opt. Lett. 27 (2002) 306.

2) M. Uesaka, K. Kinoshita, T. Watanabe, J. Sugahara, T. Ueda, K. Yoshii, T. Kobayashi, N. Hafz, K. Nakajima, F. Sakai, M. Kando, H. Dewa, H. Kotaki, and S. Kondo : IEEE Trans. Plasma. Sci. 28 (2000) 1133.

3) M. J. Bronskill, W. B. Taylor, R. K. Wolff, and J. W. Hunt: Rev. Sci. Inst. 41 (1970) 333

4) N. Chitose, Y. Katsumura, Z. Zuo, M. Domae, K. Ishigure, and T. Murakami: J. Chem. Soc. Faraday Trans. 93 (1997) 3939.

5) H. Kobayashi, Y. Tabata, T. Ueda, and T. Kobayashi: Nucl. Instrum. Methods Phys. Res. B. 24 (1987) 1073.

6) Y. Aoki, J. Yang, M. Hirose, F. Sakai, A. Tsunemi, M. Yorozu, Y. Okada, A. Endo, X. Wang, and I. Benzvi: Nucl. Instr. Meth. A455 (2000) 99.

7) Y. Aoki, T. Nakajyo, A. Tsunemi, J. Yang, Y. Okada, M. Yorozu, M. Hirose, F. Sakai, and A. Endo: Res. Chem. Intermed. 27 (2001) 689.

8) M. A. Dubinskii, V. V. Semashko, A. K. Naumov, R. Y. Abdulsabirov, and S.L. Korableva: J. Mod. Opt. 40 (1993) 1.

9) Z. L. Liu, K. Shimamura, K. Nakano, T. Fukuda, T. Kozeki, H. Ohtake, and N. Sarukura: Jpn. J. Appl. Phys. 39 (2000) L466.

10) K. Shimamura, N. Mujilatu, K. Nakano, S. L. Baldochi, Z. L. Liu, H. Ohtake, N. Sarukura, and T. Fukuda: J. Cryst. Growth. 197 (1999) 896.

11) Z. L. Liu, T. Kozeki, Y. Suzuki, N. Sarukura, K. Shimamura, T. Fukuda, M. Hirano, and H. Hosono: Opt. Lett. 26 (2001) 301.

12) T. Kozeki, Y. Suzuki, M. Sakai, H. Ohtake, N. Sarukura, Z. L. Liu, K. Shimamura, K. Nakano, and T. Fukuda: J. Cryst. Growth., 229 (2001) 501

13) Y. Suzuki, T. Kozeki, S. Ono, H. Murakami, H. Ohtake, N Sarukura, T. Nakajyo, F. Sakai, and Y. Aoki: Appl. Phys. Lett. 80 (2002) 3280. 